\title{
RESIDÊNCIA EM SAÚDE DA FAMILÍA: A PRECEPTORIA DE ENFERMAGEM LAPIDANDO SEU OBJETO DE TRABALHO
}

\author{
Eliany Nazaré Oliveira ${ }^{1}$ \\ Maria do Socorro Carneiro Linhares ${ }^{2}$ \\ Maristela Inês Osawa ${ }^{3}$ \\ Anna Vicente Santiago ${ }^{4}$ \\ Maria Alzenir C. Ponte 5 \\ Maria Socorro de Araújo Dias ${ }^{6}$
}

\section{INTRODUÇÃO}

Em 1994, o Ministério da Saúde implantou o Programa de Saúde da Família - PSF, com o intuito de reorientação do modelo brasileiro vigente. Em 1995, o Governo do Estado do Ceará, através de sua Secretaria de Saúde, definiu o PSF como sendo um programa estruturante por viabilizar a inversão do modelo de atenção à saúde até então predominantemente centrado na doença, com enfoque individual. Segundo dados da Secretaria da Saúde A implantação da Residência em Saúde da Família constitui um avanço. Reunir um programa multiprofissional e interdisciplinar com o intuito de formar profissionais qualificados para um novo modelo é um grande desafio. do Estado, até o final de dezembro de 1999 havia 730 equipes aprovadas pela Comissão Intergestores Bipartite do Ceará.

A partir da pesquisa desenvolvida por Andrade (1998) sobre o PSF no Ceará, foram identificadas varias dificuldades no processo de trabalho das equipes que atuam no PSF. Entre estas o despreparo dos profissionais para desenvolver atividades na comunidade foi a mais significativa. Este fato demonstra as limitações nos cursos de graduação de Enfermagem e Medicina na preparação dos profissionais. Para Serra (1999), do ponto de vista técnico, o maior desafio está na capacitação dos atuais profissionais e na formação dos que hoje estão nas escolas. Neste contexto, percebemos que a formação e a qualificação dos profissionais constituem um desafio a ser enfrentado e vencido.

Portanto, faz-se necessário corrigir com urgência as deficiências de conhecimentos, habilidades e prática dos membros das equipes de saúde da família em termos da atenção primária de saúde, para que os resultados esperados por esta inversão do modelo de atenção em saúde sejam alcançados, repercutindo em real impacto na qualidade de vida e conseqüente adesão desta proposta por parte da população.

Atualmente, o município de Sobral tem 31 equipes saúde da família, compostas cada uma de um médico e um ou dois enfermeiros além de auxiliares de enfermagem e agentes de saúde, totalizando cerca de 70 profissionais de nível superior, cobrindo $100 \%$ da população do município.

\footnotetext{
${ }^{1}$ Enfermeira, Mestra em Enfermagem, Professora da Universidade Estadual Vale do Acaraú - UVA

Enfermeira, Especialista em Saúde Pública, Técnica da Secretaria de Saúde e Assistência Social de Sobral.

${ }^{3}$ Enfermeira, Mestranda em Enfermagem pela UFC-CE, Professora da Universidade Estadual Vale do Acaraú - UVA.

${ }^{4}$ Enfermeira, Técnica da Secretaria de Saúde e Assistência Social de Sobral.

${ }^{5}$ Enfermeira, Especialista em Metodologia do Ensino Superior, Professora da Universidade Estadual Vale do Acaraú - UVA

${ }^{6}$ Enfermeira, Mestranda em Enfermagem pela UFC-CE, Professora da Universidade Estadual Vale do Acaraú - UVA
} 
Neste ano serão implantadas mais 9 equipes; a fim de atender a solicitação do Ministério da Saúde que oficializou, em novembro de 1999, a redução do número estimado de famílias para cada equipe, anteriormente de 4.500 pessoas (aproximadamente 1000 famílias) para 3.500 pessoas, o que representa uma média de 700 famílias para cada equipe.

Há constatação da falta de uma preparação adequada dos profissionais de saúde para atuarem na atenção primária. A idéia de criar uma Residência /Especialização em Saúde da Família no Município partiu da necessidade de capacitar os profissionais para implementar todas as ações previstas na referida estratégia. A escolha pela realização de um curso de residência, deu-se com base na necessidade de um forte componente de treinamento em serviço, além de atividades teóricas. Impulsionadas pelo desejo de melhorar este quadro, a Universidade Estadual Vale do Acaraú - UVA e a Secretaria de Saúde e Assistência Social de Sobral, com apoio do Pólo de Capacitação, Formação e Educação Permanente de Pessoal Estratégico para Saúde da Família no Ceará, elaboraram o Projeto da Residência / Especialização em Saúde da Família.

\section{A PROPOSTA DA RESIDÊNCIA}

A proposta da residência é multiprofissional, e agrega enfermeiros e médicos, há um programa básico, onde estão presentes componentes clínicos assistenciais, bem como o instrumental básico para uma abordagem coletiva e para as questões ligadas ao processo de gestão de uma unidade de saúde. Capacitar estes profissionais para atuar na estratégia Saúde da Família adequando-os para o novo modelo de atenção proposto é o objetivo geral do curso. O curso destina-se a profissionais que atuem na atenção básica de saúde, especificamente no Programa Saúde da Família- PSF.

A primeira etapa do curso compreende 460 (quatrocentas e sessenta) horas/aula teóricas a serem cumpridas no primeiro ano para obtenção do título de Especialista em Saúde da Família. Nesta fase, são desenvolvidos conteúdos teóricos que fundamentam o Programa Saúde da Família, que podem variar de 20 a 60 horas, de acordo com a importância do tema, com o seguinte conteúdo programático: I Saúde, Família e Comunidade, II Processo de Construção do SUS e PSF, III Educação Popular em Saúde, IV Planificação e Avaliação em Saúde, V Epidemiologia e Bio-Estatística Medicina Baseada em Evidência, VI Organização e Gerenciamento de Serviços, VII Vigilância à Saúde e Sistema de Informação em Saúde, VIII Metodologia do Trabalho Científico, IX Famílias em Situações de Risco, X Promoção da Saúde, XI Acompanhamento do Processo Monográfico.

Como parte do conteúdo teórico, são administradas aulas que fazem parte do Ambulatório no Contexto da Saúde da Família, inserido no conteúdo programático. São desenvolvidas através de módulos clínicos às sextas - feiras (14h às 17h). As áreas previstas são as seguintes: Problemas da mulher, da criança, do adolescente, proteção à saúde do adulto, problemas crônico - degenerativos, problemas infecciosos, urgências e procedimentos cirúrgicos.

Atividades práticas serão realizadas, a partir de fevereiro de 2000 , em serviços e programas especializados que fazem parte da rede de assistência à saúde do Município. Nestes setores, os residentes terão a oportunidade de permanecer 16 horas mensais. Neste etapa, médicos e enfermeiros serão inseridos nos serviços através do rodízio com acompanhamento de profissionais ligados à rede de saúde local, vivenciando o cotidiano desses profissionais, abstraindo conhecimentos para sua prática. Os serviços que irão compor as atividades práticas são: Unidade Clínica, Unidade Cirúrgica, Serviço de Saúde Mental - CAPS (Centro de Atenção Psicossocial), Vigilância à Saúde, Ambulatório de DSTs/AIDS, Ambulatório de Dermatologia Sanitária, Ambulatório de Neurologia, Serviço de Prevenção do Câncer e Ambulatório de Clínica.

O treinamento em serviço acontece nas unidades de saúde da família onde o profissional atua, dentro da perspectiva multiprofissional e interdisciplinar. Os residentes são acompanhados por preceptores que dedicam quatro horas semanais para essa atividade, quando são discutidas as dificuldades durante o processo de trabalho, os casos mais graves são acompanhados pelo preceptor, além da realização de trabalhos em parceria, residente - preceptor. 


\section{DINÂMICA DE ENSINO : LAPIDANDO O OBJETO DE TRABALHO DA ENFERMAGEM}

Como a principal atividade da residência está centrada no treinamento em serviço, de agora em diante, nos deteremos na descrição desta experiência que se concretiza principalmente através da preceptoria. Os residentes da área de enfermagem são supervisionados por enfermeiros, vale salientar que, como o Programa Saúde da Família se baseia numa lógica interdisciplinar, há momentos da supervisão que são realizados por outras áreas. Cada residente deve ter no mínimo uma visita semanal de quatro horas em seu local de treinamento. Estas visitas têm o intuito de acompanhar o processo de trabalho do profissional, quando serão discutidas e avaliadas as condutas dos residentes. São priorizados a organização do serviço, manejo de casos complexos, atividades dos programas, atividades comunitárias de promoção e educação em saúde.

Nossa experiência como preceptoras da enfermagem vem sendo construída com base nos problemas práticos que emergem no dia-a-dia das equipes e do trabalho de cada enfermeiros nas unidades do PSF. A implantação da residência põe-se como um desafio, pois sua característica interdisciplinar é algo que até o momento não foi desenvolvido no sistema de ensino do Brasil.

Nos quatros meses de atividades de preceptoria, já podemos descrever alguns caminhos e a dinâmica de ensino que temos trilhado. Podemos dividir essas experiências em 5 áreas: atividades coletivas de promoção à saúde, organização do serviço, mobilização e participação comunitária, atividades de pesquisa e desenvolvimento da enfermagem clínica.

A preceptoria de enfermagem dirigida para a pesquisa iniciou com o "Estudo das condições de Saúde, Educação e Vida das crianças de 5 a 9 anos da zona urbana do Município de Sobral" e tem o objetivo de atender, até abril deste ano, 4000 crianças. A pesquisa promove cursos e palestras a fim de capacitar os residentes para coletar dados fidedignos. O acompanhamento do preceptor de enfermagem da residência em saúde da família se dá no desenvolvimento da pesquisa durante a consulta de enfermagem, quando são investigados: nutrição, desenvolvimento estatu-ponderal, acuidade visual, níveis de pressão arterial, prevalência de anemia e de enteroparasitoses, como também , índices de violência e de acidentes.

Este estudo é um levantamento inédito no Brasil, pois a população estudada pouco comparece nos serviços de saúde. Os resultados dessa pesquisa constituirão um enorme banco de dados que poderá ser utilizado pelos residentes na elaboração de suas monografias de fim de curso de especialização.

A preceptoria de enfermagem tem buscado conteúdos para a prática do processo de trabalho e a reflexão dos alunos na organização dos serviços no âmbito local, de modo que atendam a dimensão do modelo proposto para o Programa Saúde da Família.

Nesse sentido, atuamos na organização do serviços através de:

- planejamento das ações intervencionistas com base nos fatos epidemiológicos da área;

- organização do fluxo do usuários na Unidade, com observância ao motivos que os levaram a procurar o serviço;

- supervisão e acompanhamento das atividades do pessoal auxiliar, inclusive com elaboração de programas de educação em serviço e readequação de papéis de acordo com as habilidades de cada um na realização de tarefas;

- gerenciamento da unidade no que diz respeito a previsão do material e equipamento necessários ao desenvolvimento das atividades da equipe.

Nesta experiência, uma das dificuldades que tem sido levantada pelos enfermeiros é de otimizar o tempo, de modo a permitir a execução de atividades que lhes foram atribuídas. É esperado que o enfermeiro seja capaz de dividir seu tempo em atividades assistências em um período e as da organização de serviços no outro. Dentro da atuação interdisciplinar das equipes do Programa Saúde da Família, o desenvolvimento do processo de gerenciamento é o que faz diferenciar o trabalho do enfermeiro do restante da equipe.

Quanto às ações coletivas de promoção à saúde, a preceptoria tem estimulado e acompanhado atividades de intervenção envolvendo grupos. Temos como exemplo grupos de idosos, de adolescentes, de mulheres em idade fértil, entre outros. Nestes espaços, procuramos enfocar a manuten- 
ção da saúde partindo do conceito de saúde não apenas como ausência de doença, resgatando assim as diretrizes da proposta do Programa Saúde da Família.

A preceptoria nas área da enfermagem clínica e cirúrgica começou com um diagnóstico das dificuldades encontradas pelos residentes em seu local de trabalho, em seguida houve a elaboração de um plano de ação teórico - prático que será desenvolvido no Laboratório de Enfermagem do Curso de Enfermagem da UVA, em um hospital de grande porte do Município e nas unidades básicas de saúde.

Nas ações de mobilização e participação popular comunitária, tivemos o desenvolvimento das oficinas de territorialização, que foram divididas em : diagnóstico da área, análise de situação e elaboração de um plano de ação. A comunidade, juntamente com a equipe do Programa Saúde da Família, construiu uma proposta de intervenção para os problemas encontrados. A preceptoria participou orientando o planejamento e execução das oficinas. Atividades como estas colocam as equipes do PSF no caminho da do resgate da cidadania e transformam a comunidade em sujeitos políticos e sociais, pois, segundo Barros (1994,p.30) "sujeito é o ser que atua, que age, que partcipa das decisões que o afetam, que luta para determinar quais são os seus direitos e exige o que for necessário para que possa usufruí-los. “

\section{BARREIRAS E AVANÇOS}

As dificuldades dizem respeito ao programa interdisciplinar. Geralmente a formação dos profissionais da área da saúde é permeada de deficiências nos aspectos que envolvem a interdisciplinaridade. Segundo Veiga Neto (1999), a formação universitária do enfermeiro é calcada num curriculum multidisciplinar representado por um amontoado de saberes não articulados, o que conduz a uma fragmentação do conhecimento produzindo uma dissociação da teoria em relação à pratica. O Programa Saúde da Família tem em sua essência o intercâmbio harmônico entre profissionais e setores e necessita de uma abordagem holística. Para isto, deve haver a complementaridade das ações entre cuidadores e serviços. Para o Ministério da Saúde a mudança do modelo tradicional exige a integração entre os vários níveis de atenção e os instrumentos para isto é o trabalho interdisciplinar. Veiga Neto (1999) define interdisciplinaridade como a relação entre saberes criando um saber integrado, uma superdisciplina.

Uma das barreiras encontradas é o perfil dos egressos, pois muitos não apresentam habilidades e competências para desempenhar suas funções especificas. Muitas deficiências são resultado de um inadequado curso de graduação. Essa constatação também foi feita por Serra (1999,p.5) em uma entrevista, quando falou: "do ponto de vista técnico o maior desafio está na capacitação dos atuais profissionais e na formação dos futuros. O Ministério da Saúde tem apoiado a formação de pólos de capacitação. A mudança tem que vir dos dois lados: o apoio à formação profissional em nível de graduação, às pesquisas e à constituição de programas de capacitação em serviço, num diálogo permanente entre as universidades e o setor público de prestação de serviços."

A implantação da Residência em Saúde da Família constitui um avanço. Reunir um programa multiprofissional e interdisciplinar com o intuito de formar profissionais qualificados para um novo modelo é um grande desafio. A supervisão de profissionais de outras áreas tem trazido resultados positivos. Temos encontrado apoio da Psicologia, Fisioterapia, Odontologia, Serviço Social, Educação Física, Terapia Ocupacional, entre outros. Desta forma, acreditamos que a Enfermagem, ao inserir-se neste projeto, está contribuindo para enriquecer sua prática, permitindo a lapidação de seu objeto de trabalho dentro desta nova proposta que é o PSF. 


\section{REFERÊNCIAS BIBLIOGRÁFICAS}

ANDRADE, F.M. O. O Programa Saúde da Família no Ceará : uma análise de sua estrutura e funcionamento. Fortaleza, 1998.

BARROS, E. O controle social e o processo de descentralização dos serviços de saúde. In: BRASIL, Ministério da Saúde. Coordenação de Informação, Educação e Comunicação, Núcleo de Estudos em Saúde Pública -NESP. Incentivo à participação Popular e Controle Social no SUS: textos técnicos para conselheiros de saúde. Brasília: IEC, 1994.

SERRA, J. A diversidade é a maior riqueza. Revista Brasileira de Saúde da Família, Ministério da Saúde, Brasília, 1999.

VEIGA NETO, A . J. Cuidar e pesquisar: a interdependência e interdisciplinaridade. In: SEMINÁRIO NACIONAL DE PESQUISA EM ENFERMAGEM, 10.,1999, Gramado-RS. Anais.... Porto Alegre: ABEn-RS/ABEn Nacional, 1999. 